\title{
Prevalence of Urinary Incontinence in CrossFit Practitioners before and during the COVID-19 Quarantine and its Relationship with Training Level: An Observational Study
}

Prevalência da incontinência urinária em praticantes de CrossFit antes e durante a quarentena pelo COVID-19 e sua relação com o nível de treinamento: Um estudo observacional

\author{
Maita Poli de Araujo ${ }^{1(0)}$ Luiz Gustavo Oliveira Brito ${ }^{2(1)}$ Alberto de Castro Pochini ${ }^{10} \quad$ Benno Ejnisman ${ }^{10}$ \\ Marair Gracio Ferreira Sartori ${ }^{10}$ Manoel João Batista Castello Girão ${ }^{1}$ () \\ ${ }^{1}$ Department of Gynecology, Escola Paulista de Medicina, \\ Universidade Federal de São Paulo, São Paulo, SP, Brazil \\ ${ }^{2}$ Department of Gynecology and Obstetrics, University of Campinas, \\ Campinas, SP, Brazil \\ Address for correspondence Maita Poli de Araujo, MD, PhD, Rua \\ Estado de Israel, 636, 04022-001, São Paulo, SP, Brazil \\ (e-mail: dramaita@gmail.com).
}

Rev Bras Ginecol Obstet 2021;43(11):847-852.

\begin{abstract}
Keywords

- crossfit

- cross-sectional study

- urinary incontinence

- COVID-19

- quarantine
\end{abstract}

Objective To compare the prevalence of urinary incontinence (UI) before and during the COVID-19 quarantine in CrossFit women and their relationship with training level. Methods A cross-sectional study was performed among 197 women practicing CrossFit. The inclusion criteria were nulliparous women, between 18 and 45 years old, who had trained, before quarantine, in accredited gyms. The exclusion criteria were not following the COVID-19 prevention protocols and having $\mathrm{UI}$ on other occasions than just sport. An online questionnaire was emailed containing questions about frequency, duration, and intensity of training and data related to the COVID-19 pandemic. The participants were invited to answer whether they were infected with COVID-19 and what treatment/recommendation they have followed. Whether UI stopped among participants, they were asked about the possible reasons why this happened. The training intensity was categorized as "the same," "decreased" or "increased."

Results The mean age of the participants was 32 years old and most (98.5\%) could practice CrossFit during the pandemic. There was a decrease in training intensity in 64\% of the respondents. Exercises with their own body weight, such as air squat (98.2\%), were the most performed. Urinary incontinence was reported by $32 \%$ of the participants before the COVID-19 pandemic, and by only $14 \%$ of them during the pandemic received

October 19, 2020

accepted

September 3, 2021
DOI https://doi.org/

10.1055/s-0041-1739463. ISSN 0100-7203. (c) 2021. Federação Brasileira de Ginecologia e Obstetrícia. All rights reserved.

This is an open access article published by Thieme under the terms of the Creative Commons Attribution License, permitting unrestricted use, distribution, and reproduction so long as the original work is properly cited. (https://creativecommons.org/licenses/by/4.0/)

Thieme Revinter Publicações Ltda., Rua do Matoso 170, Rio de Janeiro, RJ, CEP 20270-135, Brazil 


\section{Resumo}

Palavras-chave
- crossfit
- estudo observacional
- incontinência
urinária
- COVID-19
- quarentena

(odds ratio $[O R]=0.32[0.19-0.53] ; p<0.01$; univariate analysis). Practitioners reported that the reason possibly related to $\mathrm{UI}$ improvement was the reduction of training intensity and not performing doubleunder exercise.

Conclusion The reduction in the intensity of CrossFit training during the COVID-19 quarantine decreased the prevalence of UI among female athletes.

Objetivo Comparar a prevalência de incontinência urinária (IU) no CrossFit, antes e durante a quarentena por COVID-19, e sua relação com a intensidade do treinamento. Métodos Estudo observacional com 197 atletas de CrossFit. Os critérios de inclusão foram: nulíparas, 18 a 45 anos, treinando antes da quarentena em academias credenciadas. Os critérios de exclusão foram: não seguir os protocolos de prevenção da COVID-19 e ter IU em outras ocasiões que não apenas no esporte. Utilizou-se um questionário online com perguntas sobre frequência, duração e intensidade do treinamento e dados relacionados à pandemia, além de caso tivessem tido infecção pelo SARS-COV2, qual tratamento/recomendação seguiram. Caso a IU tenha parado entre as participantes, elas foram perguntadas quanto quais as possíveis razões pelas quais isso aconteceu. A intensidade do treinamento foi categorizada como "igual," "diminuída" ou "aumentada ".

Resultados A média de idade foi de 32 anos e a maioria (98,5\%) conseguiu praticar CrossFit durante a pandemia. Houve uma diminuição na intensidade do treinamento em $64 \%$ das entrevistadas. Exercícios com o próprio peso corporal, como agachamento no ar $(98,2 \%)$, foram os mais realizados. Incontinência urinária foi relatada por $32 \%$ das participantes antes da pandemia e por apenas 14\% durante a pandemia (odds ratio $[O R]=0,32[0,19-0,53] ; p<0,01)$. As atletas relataram que o motivo possivelmente relacionado à melhora da IU foi a redução da intensidade do treinamento e não realizar o exercício doubleunder.

Conclusão A redução da intensidade do treinamento de CrossFit durante a quarentena por COVID-19 diminuiu a prevalência de IU entre as atletas.

\section{Introduction}

Urinary incontinence (UI) during exercise, also termed athletic incontinence, is defined as the involuntary loss of urine during physical exercise. ${ }^{1}$ High-performance and high-impact sports, such as acrobatic trampoline, weightlifting, and long-distance running, may cause a 2-fold to increase in the odds for UI in young athletes. ${ }^{2,3}$ In middle-aged women, losing urine significantly limits physical activity. ${ }^{4,5}$

Crossfit is an example of high-intensity functional training (HIFT). The training consists of a combination of different exercise elements: endurance, gymnastics, and weightlifting exercises. CrossFit training sessions are organized into joint mobility, warm-up, technical part, and the main part. There are 12 different types of movements registered in CrossFit (-Fig. 1): air squat, front squat, overhead squat, shoulder press, push press, push jerk, deadlift, medicine-ball clean, sumo deadlift high pull, thruster, wall ball, and pull-up. ${ }^{6}$

Recent studies have shown that the prevalence of UI in CrossFit practitioners is of $\sim 30 \%$, with skipping rope the most related to this event. ${ }^{6,7}$ The etiopathogenesis of this condition is related to the increase in intra-abdominal pressure that is not balanced by the contraction of the pelvic muscles. ${ }^{8}$ In addition, the displacement of the pelvic organs during the skipping rope movement also precipitates urine loss. ${ }^{9}$

The level of physical activity is intimately related with the occurrence of UI during sport. Standards such as frequency, intensity, and training level are important to assess incontinent athletes. In this regard, physical exercises for health (at least 30 minutes a day, with moderate intensity, 5 days a week) do not have a negative effect on the pelvic floor. $^{5,6}$

Due to the COVID-19 pandemic, the Ministry of Health counselled quarantine in March 2020 and ordered the closure of nonessential services, including CrossFit gyms. ${ }^{10}$ Patients affected by the mild form of the disease were instructed to undergo social isolation, and the most severe cases were referred to the health service. ${ }^{11,12}$ However, staying physically active during the COVID-19 pandemic was a recommendation by the World Health Organization (WHO) to maintain immunity. ${ }^{9,10}$ Thus, it is not known how sportspeople have adapted their training during quarantine and whether modifying their sports schedule could impact UI. We consider that it is possible that social isolation and reduced training intensity may be beneficial for this population. Given that, we sought to compare the prevalence of UI 


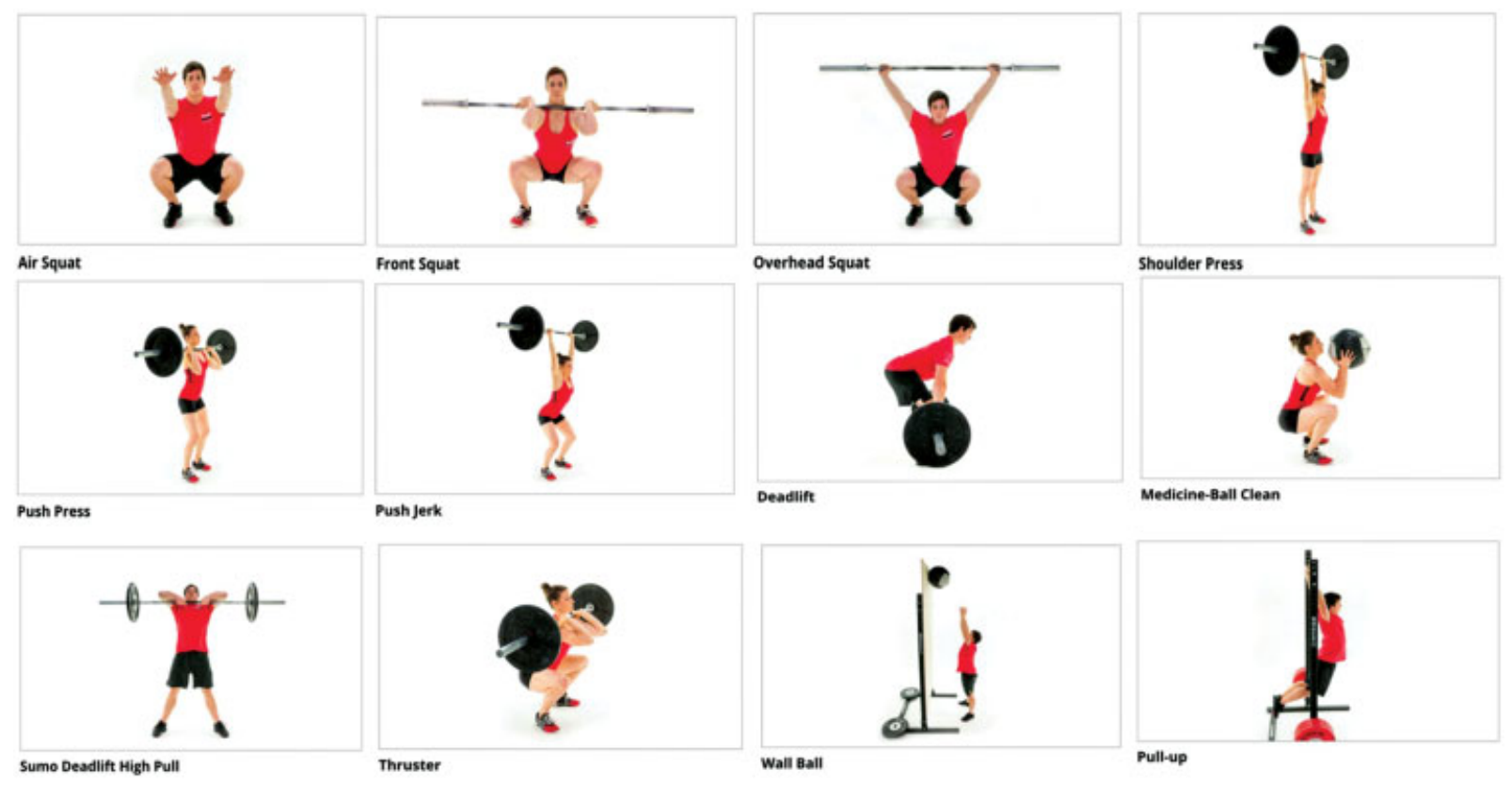

Fig. 1 Basic elements of crossfit.

before and during the quarantine by COVID-19 in CrossFit women and their relationship with training level.

\section{Methods}

The present cross-sectional study was conducted immediately after the quarantine of Brazil following the guidelines of the Strengthening the Reporting of Observational Studies in Epidemiology Statement (STROBE) guidelines. The Institutional Review Board of the Universidade Federal de São Paulo, São Paulo, state of São Paulo Brazil, approved our study protocol (CAAE 31964920.1.0000.5505) and the respondents read and signed an informed consent before starting an online survey. Thus, after signing a yes-no question to confirm their willingness to participate voluntarily, they completed a questionnaire. Patients or the public were not involved in the design, conduct, reporting, or dissemination plans of our research.

The COVID-19 pandemic in Brazil was confirmed on 25 February 2020, when a man from São Paulo tested positive for the infection. On March $27^{\text {th }}$, Brazil declared a temporary prohibition on foreign air travelers and most state governorsimposed quarantines to prevent the spread of the virus. Data collections were performed in April, May, and June 2020.

A Google Forms (https://forms.gle/9HbTvZEAgTbxExvy7) questionnaire was sent to athletes registered on the site www.crosscontinencebrazil and who had already participated in a survey on athletic incontinence ${ }^{6}$. The inclusion criteria were nulliparous women between 18 and 45 years old who had trained in accredited CrossFit gyms before quarantine in Brazil (maps.crossfit.com), at least 30 minutes a day, 3 times a week. Moreover, as inclusion criteria, were considered female athletes that were following the pandemic protocols: maintaining social distance, staying at home most of the time, not attending gyms, and practicing social isolation in case of contamination by SARS-COV2. The exclusion criteria were not following the COVID-19 pandemic protocols and patients with UI on other occasions than just sports.

The questionnaire consisted of demographic variables (age, occupation, housing, and number of people living in the same household), variables related to CrossFit training (frequency, duration, and intensity), variables related to COVID-19 (severity of symptoms, type of treatment), and urinary incontinence. Participants were asked to answer whether they were infected with COVID-19 and what treatment/recommendation they had followed. These variables were categorized into social isolation (mild clinical manifestations) or hospital treatment (moderate to severe clinical manifestations).

To evaluate symptoms of UI before and during quarantine, participants were asked: "before quarantine, have you lost urine during CrossFit training?" and "during quarantine, have you lost urine during CrossFit training?". Possible answers were yes or no. Moreover, an open-ended question was included: "if you did not lose urine during exercise this quarantine, what was the main reason". The analysis of open-ended questions was performed by categorizing the results and grouping by similarity.

Sample size calculation was based on previous reports. ${ }^{6}$ Thus, stipulating a $95 \%$ confidence interval $(\mathrm{CI})$, a hypothesized prevalence of $50 \%$ reduction of physical activity and a standard error of 5\%, a total sample of 169 subjects was established. The statistical treatment was descriptive and parametric tests were used for categorical variables, with a significance level of $p<0.05$. Univariate analysis with odds ratio (OR) and $95 \%$ CIs were also calculated for some associations.

\section{Results}

- Table 1 depicts the general characteristics of the participants. A total of 197 female athletes were enrolled in the 
present study. The mean age of the participants was 32 years old, and most of them had an adequate body mass index (82.7\%). Most participants lived in an apartment (65.5\%), and most of them reported that they lived with another person (40.1\%). Most athletes (98.5\%) managed to train CrossFit during the pandemic.

SARS-CoV 2infection manifested in a mild format in 22 athletes and treatment was performed conservatively.

- Table $\mathbf{2}$ presents the data related to duration, frequency, intensity, and training level of CrossFit of these athletes that were able to be physically active during the pandemic. The main training site for CrossFit during the quarantine was at home (55\%), followed by the outside area of the building or home (19.4\%). While most athletes maintained a high frequency of training per week ( $>5$ days) with a duration $>30$ minutes per day, training intensity reduced in $64 \%$.

- Figure 2 displays the most prevalent exercises chosen by the respondents. In general, exercises using their own body weight, such as air squat, were the most performed (98.2\%), followed by push up (92.2\%) and burpee (89.1\%). Exercises that needed specific materials, such as medicine ball and wall ball, were practiced by less than half of the athletes.

Regarding UI, before the quarantine, $32 \%$ of the athletes reported the symptom and, during the quarantine, only $14 \%$ of the participants reported UI. This reduction was statistically significant $(\mathrm{OR}=0.32[0.19-0.5307] ; p<0.001)$ by uni-

Table 1 General characteristics of female CrossFit practitioners during the COVID-19 quarantine

\begin{tabular}{|c|c|c|}
\hline Variable & $n$ & $\%$ \\
\hline \multicolumn{3}{|c|}{ Type of housing during the quarantine } \\
\hline Home & 68 & 34.5 \\
\hline Apartment & 129 & 65.5 \\
\hline \multicolumn{3}{|c|}{ Number of people in the household } \\
\hline Alone & 26 & 13.2 \\
\hline 2 & 79 & 40.1 \\
\hline 3 & 54 & 27.4 \\
\hline$>3$ & 38 & 19.3 \\
\hline \multicolumn{3}{|l|}{ Body Mass Index (Kg/m2) } \\
\hline Underweight $(<18.5)$ & 0 & \\
\hline Normal (18.5-24.9) & 163 & 82.7 \\
\hline Overweight (25-29.9) & 27 & 13.7 \\
\hline Obese $(>30)$ & 7 & 3.6 \\
\hline \multicolumn{3}{|c|}{ Reported COVID-19 symptoms } \\
\hline Yes & 22 & 11.2 \\
\hline No & 175 & 88.8 \\
\hline \multicolumn{3}{|c|}{ Type of treatment for COVID-19 } \\
\hline Social isolation (home) & 22 & 100 \\
\hline Hospitalization & 0 & 0 \\
\hline \multicolumn{3}{|c|}{ Were you able to train CrossFit during the quarantine? } \\
\hline Yes & 194 & 98.5 \\
\hline No & 3 & 1.5 \\
\hline
\end{tabular}

Table 2 Place, frequency, duration, and intensity of CrossFit training during the quarantine

\begin{tabular}{lll}
\hline Variables & $n$ & $\%$ \\
\hline Location where you trained during the quarantine & & \\
Indoor house or apartment & 108 & 55 \\
On a small balcony in the house or apartment & 26 & 13.4 \\
Outside the house or apartment & 58 & 19.4 \\
In the garage of the house or apartment & 2 & 1.9 \\
Frequency of training/week & & \\
3 & 28 & 14.4 \\
4 & 22 & 11.3 \\
5 & 48 & 24.7 \\
6 & 43 & 22.2 \\
7 & 53 & 27.3 \\
Training duration (minutes) per day & & \\
30 & 36 & 18.6 \\
$30-60$ & 107 & 55.2 \\
$>60$ & 51 & 26.3 \\
Intensity of CrossFit training during the quarantine & \\
Increased & 0 & 0 \\
Same & 69 & 36 \\
Decreased & 126 & 64 \\
\hline
\end{tabular}

variate analysis (-Table 3 ). When the athletes were asked what reasons they considered to be the cause for UI improvement $(n=36), 22$ reported they had reduced the training intensity and 14 stopped doing exercises with rope.

\section{Discussion}

Our study has found a $64 \%$ reduction on CrossFit training during the quarantine and an $18 \%$ reduction of UI during this period. The sudden onset of a state of social isolation implies a radical change in the lifestyle of the population, such as the level of physical activity, eating habits, and sleep. ${ }^{13}$ Thus, many medical societies released information on how to avoid a sedentary lifestyle during the COVID-19 pandemic. ${ }^{14,15}$ At the same time, gyms and elite athletes provided free online training to help people stay active at home. ${ }^{16}$ One of the main characteristics of CrossFit training is that it is performed in a gym equipped with rings, bars, and weights. ${ }^{17}$ Therefore, one of the possibilities of the present study was that CrossFit practitioners would not be able to train at home. However, it was observed that $98.5 \%$ of the interviewees maintained their training, adapting their exercise routine indoors.

Exercises that needed special equipment, such as wall ball and medicine ball, were the least practiced by the participants ( 10.9 and $15.5 \%$, respectively), while exercises using the own body weight of the participants, such as air squat and push up, were maintained by most athletes (98.4 and $98.2 \%$, respectively). Another interesting fact is that the specificity of CrossFit training involves the association of Olympic lifting exercises (squats, sprints, throws); aerobic 


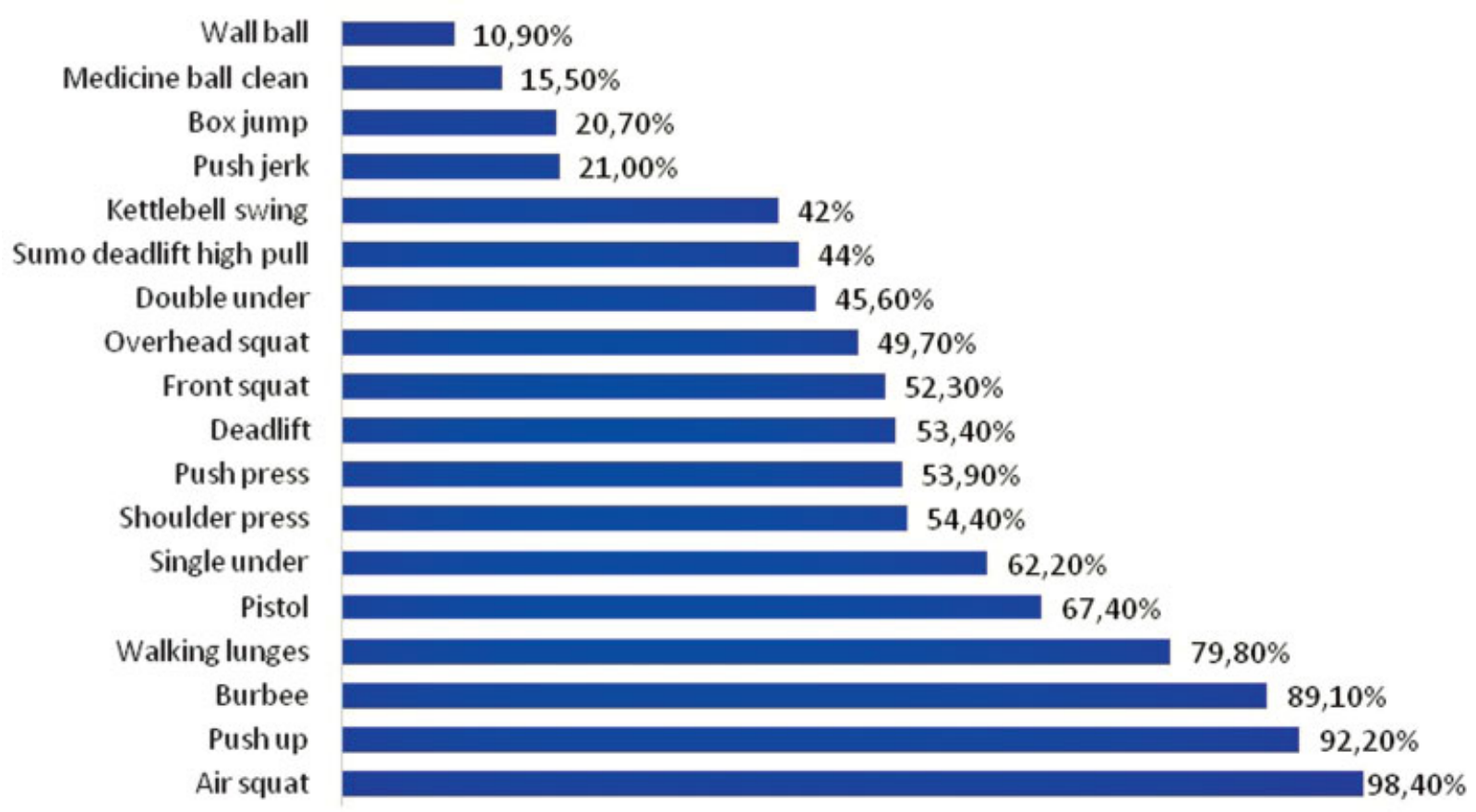

$0,00 \% 10,00 \% 20,00 \% 30,00 \% 40,00 \% 50,00 \% 60,00 \% 70,00 \% 80,00 \% 90,00 \% 100,00 \%$

Fig. 2 Types of Crossfit exercises performed at home during the COVID-19 pandemic.

Table 3 Urinary incontinence before and after the quarantine

\begin{tabular}{llll}
\hline & $\begin{array}{l}\text { Before the } \\
\text { quarantine }\end{array}$ & $\begin{array}{l}\text { During the } \\
\text { quarantine }\end{array}$ & Total \\
\hline With UI & $63(32 \%)$ & $27(14 \%)$ & 90 \\
Without UI & $134(68 \%)$ & $170(86 \%)$ & 304 \\
Marginal column totals & 197 & 197 & 394 \\
\hline
\end{tabular}

Abbreviation: $\mathrm{UI}$, urinary incontinence.

z-statistic $=4.427 ; p<0.001 ; \mathrm{OR}=0.32[0.19-0.53]-$ univariate analysis.

exercises (such as rowing, running, and cycling) and gymnastics movements (such as handstands, parallel bars, rings, and bars). ${ }^{18}$ In this sense, it was a surprise to realize in our study that the interviewees were able to maintain their physical exercise routine in their homes, even in small environments such as a balcony.

Studies show that $\sim 5 \%$ of CrossFit practitioners have some degree of addiction to exercise. ${ }^{19}$ If this motivation may have been the explanation for maintaining their routine at home, on the other hand, it concerns the effect of highintensity exercise on the immune system. It is observed that 22 athletes reported having symptoms of COVID-19 and, as a treatment, they did social isolation. It has been shown that high-intensity training can lead to lymphocyte apoptosis and predispose to immunosuppression. ${ }^{20}$ Even in recreational athletes, a CrossFit training protocol with 10 repetitions of horizontal bench press, deadlifts, and squats, performed at $75 \%$ of a maximum repetition, and without a break, significantly increases interleukin-6 (IL-6). In terms of COVID-19, data suggest that IL-6 may play a key role in the evolution of the inflammatory immune response that causes acute respiratory distress syndrome. ${ }^{21}$

The reduction of UI during exercise after starting the quarantine was statistically significant and the reasons provided by the respondents were the interruption of double under exercises and the reduction in the intensity of the training. Double under is the CrossFit movement that most frequently increases the intra-abdominal pressure $(429 \mathrm{~cm}$ $\mathrm{H}_{2} \mathrm{O}$ ), with this value being one of the highest ever attributed to any sporting gesture. ${ }^{5}$ In a previous study performed from our group, it was the exercise mostly associated with UI. ${ }^{6}$ Thus, the interruption of this exercise in the quarantine explains the improvement in UI. Another important fact is that the increase in intra-abdominal pressure in CrossFit exercise varies with the intensity of the training, repetitions, and the use or not of load. ${ }^{8}$ In this sense, the quarantine may have indirectly assured the protective effect to the pelvic floor, due to the difficulty in using training accessories and to the decreased training intensity.

The volume of training has been reported in previous studies as a risk factor for athletic incontinence. Women who play high-impact sports or who have a higher volume of training should be aware of the symptoms associated with pelvic floor dysfunction. ${ }^{9,10}$ The level of exercise can be calculated based on the time (in minutes) usually spent per week or the intensity (light, moderate, intense). Normally, athletes, from any modality and who train for competitive purposes, are at twice the risk for UI when compared with sedentary individual.

Some reports indicate that physical inactivity will persist long after we recover from the COVID-19 pandemic. ${ }^{13}$ In this sense, maintaining the CrossFit training routine at home was 
a positive element for future health. ${ }^{22}$ Moreover, our findings may suggest that the general gynecologist may counsel UI women who practice CrossFit to reduce training intensity or to replace series containing jumping exercises, as this may benefit their urinary symptoms. These women may be physically active with no impact in their pelvic floor. Moreover, we may extend this by noticing that, even during a major pandemic, physical activity was not completely impaired. This experience may prepare us for future waves of this pandemic (or to others that might come).

To our knowledge, this is the first study analyzing the impact of COVID-19 quarantine on CrossFit training and the repercussion on UI during exercise. The limitations of the present study include the use of an online questionnaire, the lack of physical examination, and the self-report of COVID-19 symptoms without laboratorial confirmation. Despite sample size calculation having been performed, there is a risk of type 2 error regarding the analysis of the associated factors for the reduction of CrossFit training, and for this reason we opted to not perform a multivariate analysis.

\section{Conclusion}

In conclusion, the COVID-19 quarantine improved athletic incontinence in CrossFit practitioners due to decreased training intensity and to interruption of higher intra-abdominal pressure exercises.

\section{Contributions}

Conception and design, data collection or analysis, and interpretation of data: Araujo M. P.; Brito L. G. O.. Writing of the article or critical review of the intellectual content: Araujo M. P.. Final approval of the version to be published: Pochini A. C.; Ejnisman B.; Sartori M. G. F.; Girão M. B. C..

\section{Conflict of Interests}

The authors have no conflict of interests to declare.

\section{References}

1 Araujo MP, Sartori MGF, Girão MJBC. Athletic incontinence: proposal of a new term for a new woman. Rev Bras Ginecol Obstet. 2017;39(09):441-442. Doi: 10.1055/s-0037-1605370

2 Almousa S, Bandin Van Loon A. The prevalence of urinary incontinence in nulliparous female sportswomen: A systematic review. J Sports Sci. 2019;37(14):1663-1672. Doi: 10.1080/ 02640414.2019 .1585312

3 Cerruto MA, Balzarro M, Rubilotta E, Procesalli T, Latini MT, Porcaro AT, et al. Lower urinary tract and gastrointestinal dysfunction in sportswomen: a systematic review and meta-analysis of observational studies. Minerva Urol Nefrol. 2020;72(06): 698-711. Doi: 10.23736/S0393-2249.19.03582-3

4 Alves JO, Luz STD, Brandão S, Da Luz CM, Jorge RN, Da Roza T. Urinary incontinence in physically active young women: prevalence and related factors. Int J Sports Med. 2017;38(12):937-941. Doi: $10.1055 / \mathrm{s}-0043-115736$

5 Cardoso AMB, Lima CROP, Ferreira CWS. Prevalence of urinary incontinence in high-impact sports athletes and their association with knowledge, attitude and practice about this dysfunction. Eur J Sport Sci. 2018;18(10):1405-1412. Doi: 10.1080/ 17461391.2018.1496146
6 Poli de Araújo M, Brito LGO, Rossi F, Garbiere ML, Vilela ME, Bittencourt VFCross Continence Brazil Collaboration Group. Prevalence of female urinary incontinence in crossfit practitioners and associated factors: an Internet population-based survey. Female Pelvic Med Reconstr Surg. 2020;26(02):97-100. Doi: 10.1097/SPV.0000000000000823

7 Yang J, Cheng JW, Wagner H, Lohman E, Yang SH, Krishinger GA, et al. The effect of high impact crossfit exercises on stress urinary incontinence in physically active women. Neurourol Urodyn. 2019;38(02):749-756. Doi: 10.1002/nau.23912

8 Gephart LF, Doersch KM, Reyes M, Kuehl TJ, Danford JM. Intraabdominal pressure in women during CrossFit exercises and the effect of age and parity. Proc Bayl Univ Med Cent. 2018;31(03): 289-293. Doi: 10.1080/08998280.2018.1446888

9 Bø K, Nygaard IE. Is physical activity good or bad for the female pelvic floor? A narrative review. Sports Med. 2020;50(03): 471-484. Doi: 10.1007/s40279-019-01243-1

10 Croda J, Oliveira WK, Frutuoso RL, Mandetta LH, Baia-da-Silva DC, Brito-Sousa JD, et al. COVID-19 in Brazil: advantages of a socialized unified health system and preparation to contain cases. Rev Soc Bras Med Trop. 2020;53:e20200167. Doi: 10.1590/00378682-0167-2020

11 Barreto ML, Barros AJD, Carvalho MS, Codeço CT, Hallal PRC, Medronho RA, et al. [What is urgent and necessary to inform policies to deal with the COVID-19 pandemic in Brazil?] Rev Bras Epidemiol. 2020;23:e200032. Doi: 10.1590/1980-549720200032

12 Ribas RM, Campos PA, Brito CS, Gontijo-Filho PP. Coronavirus Disease 2019 (COVID-19) and healthcare-associated infections: Emerging and future challenges for public health in Brazil. Travel Med Infect Dis. 2020;37:101675. Doi: 10.1016/j.tmaid. 2020.101675

13 Hall G, Laddu DR, Phillips SA, Lavie CJ, Arena R. A tale of two pandemics: How will COVID-19 and global trends in physical inactivity and sedentary behavior affect one another? Prog Cardiovasc Dis. 2021;64:108-110. Doi: 10.1016/j.pcad.2020.04.005

14 Fallon K. Exercise in the time of COVID-19. Aust J Gen Pract. 2020

15 Chen P, Mao L, Nassis GP, Harmer P, Ainsworth BE, Li F. Coronavirus disease (COVID-19): The need to maintain regular physical activity while taking precautions. J Sport Health Sci. 2020;9(02): 103-104. Doi: 10.1016/j.jshs.2020.02.001

16 Gilat R, Cole BJ. COVID-19, medicine, and sports. Arthrosc Sports Med Rehabil. 2020;2(03):e175-e176. Doi: 10.1016/j.asmr. 2020.04 .003

17 Jansen JJ, van Dam NM, Hoefsloot HC, Smilde AK. Crossfit analysis: a novel method to characterize the dynamics of induced plant responses. BMC Bioinformatics. 2009;10:425. Doi: 10.1186/14712105-10-425

18 Meyer J, Morrison J, Zuniga J. The benefits and risks of crossfit: a systematic review. Workplace Health Saf. 2017;65(12):612-618. Doi: $10.1177 / 2165079916685568$

19 Lichtenstein MB, Jensen TT. Exercise addiction in CrossFit: Prevalence and psychometric properties of the Exercise Addiction Inventory. Addict Behav Rep. 2016;3:33-37. Doi: 10.1016/j. abrep.2016.02.002

20 Cadegiani FA, Kater CE, Gazola M. Clinical and biochemical characteristics of high-intensity functional training (HIFT) and overtraining syndrome: findings from the EROS study (The EROSHIFT). J Sports Sci. 2019;37(11):1296-1307. Doi: 10.1080/ 02640414.2018.1555912

21 McGonagle D, Sharif K, O'Regan A, Bridgewood C. The role of cytokines including interleukin-6 in COVID-19 induced pneumonia and macrophage activation syndrome-like disease. Autoimmun Rev. 2020;19(06):102537. Doi: 10.1016/j.autrev.2020.102537

22 Toresdahl BG, Asif IM. Coronavirus Disease 2019 (COVID-19): considerations for the competitive athlete. Sports Health. 2020; 12(03):221-224. Doi: 10.1177/1941738120918876 